\title{
INNOVATIVE USE OF CORRUGATED RUBBER DRAIN FOR NERVE PROTECTION
}

KEY WORDS:

Iatrogenic, orthopaedics, Corrugated rubber drain(CRD) nerve injury

\section{Rahul Agarwal}

Pawan Kumar

Rawat*

Yogesh Ahuja

Irshad Ahmad Ganie

\section{Pankaj Singh}

\section{Arpit Vishnoi}

Assistant Professor, Department of Orthopaedics, SGRRIM\&HS, Dehradun, Uttarakhand, India.

Associate Professor, Department of Orthopaedics, SGRRIM\&HS, Dehradun, Uttarakhand, India. *Corresponding Author

Junior Resident, Department of Orthopaedics, SGRRIM\&HS, Dehradun, Uttarakhand, India.

Senior resident, Department of Orthopaedics, SGRRIM\&HS, Dehradun, Uttarakhand, India.

Junior Resident, Department of Orthopaedics, SGRRIM\&HS, Dehradun, Uttarakhand, India.

Junior Resident, Department of Orthopaedics, SGRRIM\&HS, Dehradun, Uttarakhand, India.

Background: Nerves are at great risk of injury during orthopaedic surgeries. Such injuries lead to major disability in patients. Based on the various studies on patients suffering from such injuries during surgeries, we studied a list of

E factors leading to intra-operative nerve injuries. One factor leading to such injuries is application of various materials 글 around nerves to protect them, which may cause undue traction on nerves.

Methods: We conducted a study in 25 patients operated for different fractures and used corrugated rubber drain to protect nerves during various surgical procedures.

Results: With this innovative use of easily available corrugated rubber drain,we observed that none of our patients suffered from intra-operative nerve injury. observed that none of our patients suffered from intra-operative nerve injury. Conclusion: Our aim is to introduce the use of corrugated rubber drain to protect nerves from injuries during various surgical procedures. Although, a thorough understanding of anatomy, meticulous dissection and appreciation of pathoanatomy in fracture surgery is of utmost importance to reduce the risk of iatrogenic injuries.

\section{INTRODUCTION}

Surgical procedures carry various risks depending on the surgical site. Injuries to the neurovascular structures is amongst one of the common complications .Incidence of peripheral nerve injuries can range from $0.03 \%$ to $0.11 \% .^{[1][2]}$

Data from various studies shows that incidence of nerve injuries in trauma can range from $2 \%$ to $3 \% \cdot{ }^{[3]\left[{ }^{4]}\right.}$ Distortion of anatomy because of trauma leads to an increased risk of damage of nerves during surgery due to disturbed anatomical planes due to edema, hematoma or scarring. Orthopaedic surgeries require manipulation of bones and insertion of reduction instruments which may require the use of power tools, instrumentation and insertion of implants, which also pose an additional danger to the surrounding structures.

Nerve injuries cause pain, paralysis, loss of protective sensation and disability. These injuries adversely influence the outcome of the index procedure and may result in disability to patient, litigation, increasing the financial burden on surgical services.

There are various methods which can be employed to protect the nerves from injuries during surgical procedures.

Commonly employed materials include use of glove sleeves, nasogastric tube, gauze pieces, low-thickness elastic tape or low-thickness Latex tape ${ }^{[5]}$.With the use of these techniques, few cases of intra-operative nerve injuries are still seen.

So, we employed the use of $250 \mathrm{~mm} \mathrm{X} 25 \mathrm{~mm}$ size corrugated rubber drain to protect nerves during surgeries.

Our aim is to introduce and discuss the benefits of the use of Corrugated Rubber Drain to protect nerves from perioperative injuries caused by various mechanisms.

www.worldwidejournals.com
Mechanism Of Nerve Injuries In Orthopaedic Surgeries

In orthopaedic surgeries, nerve injuries are disabling and may have medicolegal implications ${ }^{[6]}$ Nerves may be injured at the time of trauma due to penetrating wounds, laceration from fracture fragments, traction while attempting reduction, deformity at fracture site, compression between fracture fragments, due to edema or hematoma.

During surgical stabilization of fractures, while open reduction and internal fixation is done, normal anatomical landmarks may be masked by swelling, safe corridors may be breached and normal tissue planes are disturbed. In open treatment of fractures, these factors pose more danger for injuries to neurovascular structures. ${ }^{[7][8]}$

During surgical procedures, the use of power tools and sharp instruments like k-wires, pins, drill bit, retraction by levers or retractors, application of various implants like plates, intramedullary devices like nails, screws, application of external fixators or use of diathermy; all these tools risk nerve for injuries by direct penetration by instruments, tethering or wrapping into the instruments or nearby structures or thermal injury due to heat production by power tools and diathermy. ${ }^{[7][8]}$

There are several mechanisms by which nerves can be damaged during open surgery (Table 1).

\section{Prevention of Nerve Injuries}

A sound knowledge about the anatomy of surgical site is of prime importance in understanding the preventive strategies.

A thorough preoperative examination is important to identify conditions that predispose the patient to nerve injury (due to disturbed anatomy in cases of trauma or prolonged scarring of tissues) and existing neurological dysfunction. 
During surgery, careful positioning of the patient, use of protective padding (where nerves lie superficial), careful application of regional blocks under guidance and careful application of tourniquets with proper pressure are important components of care.

Excessive forceful movements of limbs should be avoided and limbs should be kept in neutral position unless required for surgery.

Consideration should be given to avoid giving more potent local anaesthetics (like tetracaine, bupivacaine, etidocaine ) and vasoconstrictors in patients with preexisting neurological disease or peripheral nerve injury.Less potent anaesthetics (like Lidocaine) can be used safely in such patients. ${ }^{[1]]}$

Nerves are at more risk during open surgeries, during dissection, fracture reduction, instrumentation (like reaming, drilling or retraction ) and implant fixation. Many procedures are employed in past to protect nerves from damage, but there is a very little mention of such procedures in literature.

Prior to the use of corrugated rubber drain, we used to apply surgical glove, gauze, nasogastric tube ( $6 \mathrm{Fr}$ or $8 \mathrm{Fr}$ ) to protect and retract the nerves away from the surgical field. In literature, use of low-thickness elastic or latex tapes is also mentioned. ${ }^{[5]}$ As per our experience, we found that these techniques are less effective for protection of nerves as many problems are faced due to less thickness and small diameter of these materials leading to easy breakage leaving residues at surgical sites and also these materials are not capable of providing good hold of nerves and lead to an acute angulation of nerves during retraction which can cause neurological complications such as traction injury or neuropraxia. Also, there are more chances of nerves being wrapped up in the drill bits , k wires or screws with use of these materials.

Table 1 : Various Factors Which Can Cause Iatrogenic Surgeries ${ }^{[9][10]}$

\section{Causes of nerve injuries during surgery}

- Sharp injury- by scalpel

- Incorrect placement of retractors

wires and reamers

- Use of diathermy

- Implant placement - plates, screws , k-wires

- Traction of nerve during reduction/ by retractors

\section{- Impingement / penetration due to} fractured bone ends Injuries To Nerves During Open Orthopaedic

- Use of power drills, drill bits, sharp

Surgeries were performed using standard operative steps. After dissection and nerve isolation, a $250 \mathrm{~mm}$ X $25 \mathrm{~mm}$ size corrugated rubber drain (Figure 1) was used to secure and protect the isolated Sciatic nerve in acetabulum surgeries, ulnar nerve in distal humerus surgeries and radial nerve in humerus shaft surgeries. Once the nerve is protected with drain, two ends of Corrugated rubber drain were sutured on itself (Figure. 2) and a small artery forceps was attached at its ends. Nerve was retracted during various surgical steps using this drain. This can be slided near the working sites (Figure 3, 4). Drain was utilized to manipulate the nerve during various steps of surgery. After implant fixation, drain is safely removed. Before closure, it was ensured that there is no other factor causing nerve impingement. If deemed necessary, neurolysis or transposition of nerve was done in cases with scarring of tissues.

Post operatively, neurological evaluation respective to nerves exposed at the surgical site was performed in all the patients on subsequent follow-up. Maximum time for the recovery from effect of regional block was taken as 12 hours and clinical examination made after that was taken into consideration.

Outcome after a nerve injury varies according to the functions of nerve affected (sensory, motor, or combined). Injury to a motor nerve results in loss of functions in supplied muscles, whereas injury to a sensory nerve results in sensory loss in ther nerve distribution. ${ }^{[12,13]}$

Motor function of the nerves tested respective to the muscles supplied, using Manual muscle testing as per Medical Research Council grades. Sensory modalities (Touch, Pain, Temperature, vibration and two point discrimination) were tested to assess sensory functions. ${ }^{[14]}$ (Table 3 )

Table 3: Nerves And Their Motor And Sensory Functions Tested

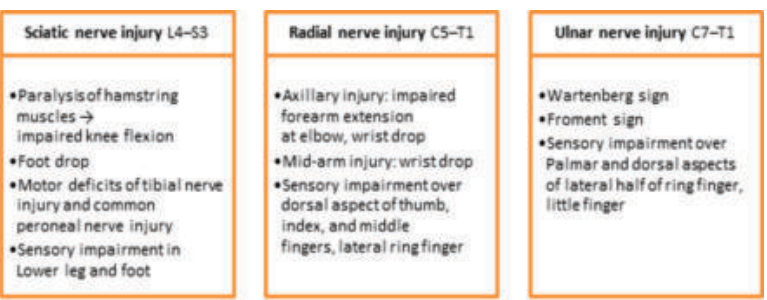

Protected In Various Surgeries

\begin{tabular}{|c|c|c|}
\hline $\begin{array}{c}\text { Surgery } \\
\text { performed }\end{array}$ & Nerve Protected & Number of cases \\
\hline $\begin{array}{c}\text {-Acetabulum } \\
\text { fracture } \\
\text {-Distal humerus } \\
\text { fracture } \\
\text {-Humeral shaft } \\
\text { fracture }\end{array}$ & $\bullet$ - Sciatic nerve & $\bullet 6$ \\
\hline
\end{tabular}

\section{MATERIALS AND METHODS}

Patients undergoing elective open surgeries in the department orthopaedics at Shri Mahant Indiresh Hospital, Dehradun for fracture acetabulum, fractures of distal humerus and humeral shaft fractures were selected (Table 2).Study was conducted in 25 patients from January, 2020 to May ,2020.

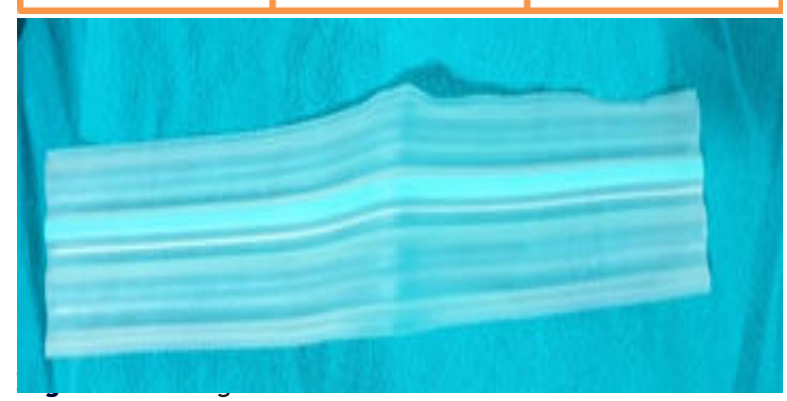

|www.worldwidejournals.com $\mid$ 




Ulnar Nerve During Surgery ; 2B- Drain Secured With Sutures At The End

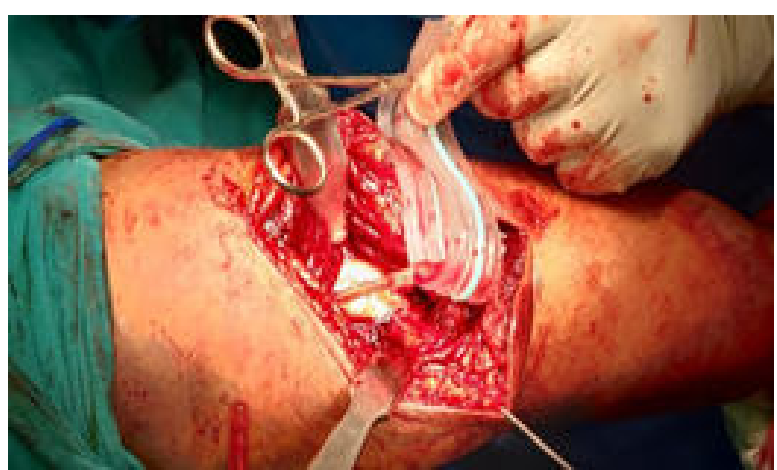

Nerve In Fracture Humerus Surgery With Artery Forceps At Drain Ends.

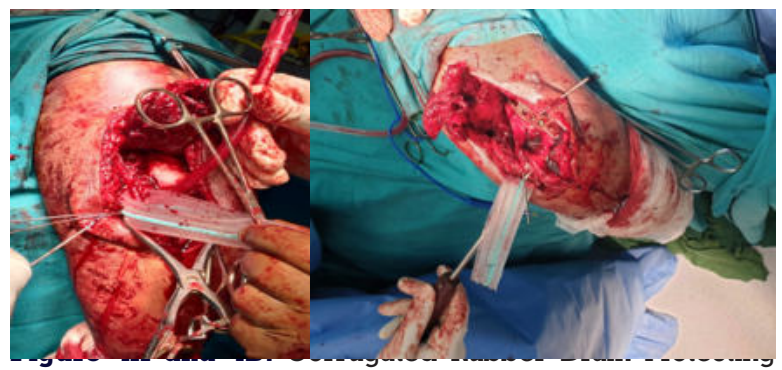

Nerve During Instrumentation

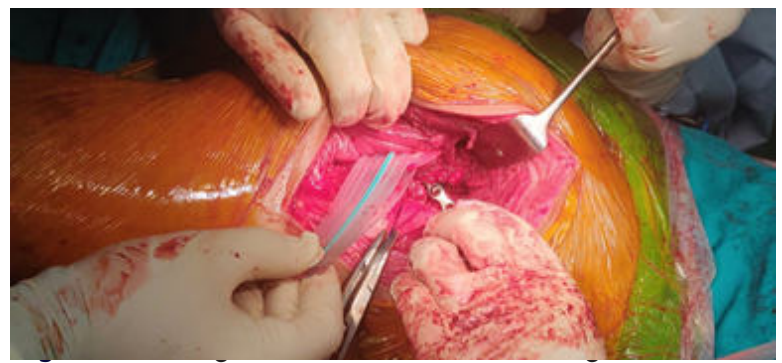

During Instrumentation In Acetabulum Surgery

\section{RESULTS}

Total of twenty five patients were included in the study. The age of patients was from 26 to 70 years. Six patients were operated for acetabular fractures, ten were operated for distal humerus fractures and nine were operated for humerus shaft fractures. Pre-operatively, none of our patients were having nerve injury. On post operative evaluation of the nerves protected during open surgical procedure, none of the patients were found to have signs of injuries related to the nerve protected during the surgical procedures.

\section{CONCLUSION AND RECOIMMENDATIONS}

Nerve palsies are very commonly associated with surgical procedures. The potentially devastating nature of nerve injuries makes it a topic of interest. Many possible risk factors for intra-operative nerve injuries can be there, instrumentation during orthopaedic surgeries being the most important. Disturbed anatomy in cases of fractures leading to difficult open procedures in trauma cases, further predisposes to injuries. Various techniques are employed by different surgeons to protect nerves during surgeries.

This technique of utilization of corrugated rubber drain of size $250 \mathrm{~mm} \times 25 \mathrm{~mm}$ for nerve protection is innovative in form as CRD being thicker than generally used materials protect nerves from getting tethered or wrapped up with use of instruments (like $\mathrm{k}$-wires, drills, placement of plates and screws). CRD is more firm than the conventionally used materials, so the chance of nerve getting wrapped up is zero. Also it protects nerves from thermal injuries caused by the use of diathermy or drill bits. CRD being wider than previously used materials, prevents acute angulation of nerves during retraction and decreases chances of nerve injuries due to traction.

Power tools can be used adjacent to the CRD without any risk of nerve being damaged. Using this technique, nerve position can be manipulated easily, nerve can be lifted away from the bone which helps in easy placement of implant over bone surface, thereby preventing nerve damage.

Various advantages of CRD include its easy availability, cost effectiveness, protection of nerves from instruments, prevents nerve injuries due to fractured bone ends or diathermy and ease of sliding CRD to the site of instrumentation. Also, this method can be employed to protect vascular structures as well.

Possible limitations of CRD use could be a need of more dissection for the placement of drain around the nerves. Another possible disadvantage could be its limited utility for small nerves.

Some precautions to be employed while using this technique include use of small artery forceps at the ends as heavy artery forceps can lead to excessive traction force on nerves.

Surgeons should be aware of the inherent surgical risks and anatomy. However, this technique cannot override the sound knowledge of anatomy and meticulous dissection but a judicious use of Corrugated rubber drain can serve as a great tool to prevent iatrogenic nerve injuries.

\section{REFERENCES}

1. Welch MB, Brummett CM, Welch TD, Tremper KK Shanks AM Guglani P, et al. Perioperative peripheral nerve injuries: A retrospective study of 380,680 cases during a 10-year period at a single institution. Anesthesiology 2009;111:490-7.

2. Esquivel-Enriquez P, Perez-Neri I, Manrique-Carmona L. Neurosurgical position causes peripheral nerve injuries?.Cirugia y cirujanos 2017;85:493-8.

3. Noble J, Munro CA, PrasadVS, Midha R. Analysis of upper and lower extremity peripheral nerve injuries in a population of patients with multiple injuries. $J$ Trauma. 1998 Jul. 45 (1):116-22.

4. Lad SP, Nathan JK, Schubert RD, Boakye M. Trends in median, ulnar, radial, and brachioplexus nerve injuries in the United States. Neurosurgery. 2010 May. 66 (5):953-60.

5. Ali Hassani, Sarang Saadat, Roya Moshiri, Solaleh Shahmirzad, Amin Hassani, Nerve Retraction During Inferior Alveolar Nerve Repositioning Procedure: A New Simple Method and Review of the Literature.J Oral Implantol 1 July 2015; 41 (S1):391-394.

6. Casali MB, Blandino A, Del Sordo S, Vignali G, Novello S, Travaini G, et al. Alleged malpractice in orthopaedics. Analysis of a series of medmal insurance claims.J Orthop Traumatol 2018;19:7.

7. Alvites R, Caseiro AR, Pedrosa SS, Branquinho MV, Ronchi G, Geuna S, et al. Peripheral nerve injury and axonotmesis: State of the art and recent advances. Cogent Med 2018;5:1-45.

8. Hoppenfeld S, de Boer P, Buckley R. Surgical Exposures in Orthopaedics:The Anatomic Approach. 5th ed. Philadelphia, United States: Lippincott Williams andWilkins;2016.

9. Kretschmer T, Heinen CW, Antoniadis G, Richter HP, Konig RW. Iatrogenic nerve injuries. In: Spinner RJ, Winfree CJ, editors. Neurosurg Clin N Am. Vol. 20.Philadelphia:W.B.Saunders Company;2004.pp.73-90

10. Wilbourn AJ.Iatrogenic nerve injuries. Neurol Clin. 1998;16:55-82.

11. McLure HA, Rubin AP. Review of local anaesthetic agents. Minerva Anestesiol. 2005 Mar;71(3):59-74.

12. Sunderland S.Nerves and Nerve Injuries. London: Churchill Livingstone; 1978.

13. Mackinnon SE.Nerve Surgery. NewYork:Thieme;2015.

14. M. O. O'Brien,Aids to the Examination of the Peripheral Nervous System, Edinburgh, Saunders, 5th edition, 2010 